ISSN: 2318 - 1966

v. 3, n. 3

jan - jun 2015

Dossiê

\title{
DIL: THE CRYING GAME, ESPECTATORALIDADE E AGENCIAMENTO TRANS EM TRAÍDOS PELO DESEJO
}

Marcelo Spitzner

Doutorando e Mestre em Literatura pela

Universidade Federal de Santa Catarina (UFSC)

\begin{abstract}
RESUMO
Este artigo, através de uma perspectiva transfeminista e queer, discute um recorte do filme Traídos pelo Desejo, como pertence a um campo que convencionalmente tem-se chamado de Trans Cinema. Através da discussão do filme busca-se, além de problematizar o conceito de gaze, a partir de um viés binário, propor uma espectatoralidade agencial da personagem trans. Essa espectatoralidade e agenciamento da personagem Dil são possíveis através de um momento, que pode ser observado em vários filmes do Trans Cinema, em que o personagem experimenta uma ruptura com o sentimento de medo ou da exposição a potencial violência, é um momento de intenso engajamento fílmico que permite uma fuga temporária do domínio cinematográfico dos efeitos negativos de cenas constrangedoras. A esse momento poderíamos chamar de "válvula de escape" e pode estar associado a diversos elementos, tais como sonho, fantasia, dança, etc. Nesse filme, associo-o a performance da música (ou música-escape) The Crying Game.
\end{abstract}

Palavras-chave: Trans Cinema, Espectatoralidade, Gaze, Agenciamento, Teoria queer

DILL: TRANS SPECTATORSHIP AND AGENCY IN THE CRYING GAME

\begin{abstract}
This article, through a transfeminist and queer perspective, discusses a piece of the film The Crying Game, as it pertains to a field that has been conventionally called Trans Cinema. Through the discussion of the film and the problematization of the concept of gaze, as a binary bias, propose an agential spectatorship of the trans character. This spectatorship and agency of Dil are possible through a moment that can be seen in several films of the Trans Cinema, in which the character experiences a break with the feeling of fear or being exposed to potential violence, it is a moment of intense filmic engagement allowing a temporary escape from negative effects of scenes of constraint. This moment that we can call a "safety valve", or an exit scape, and can be associated with various elements such as dream, fantasy, dance, etc. In this film, I associate it to the performance of the music (or song-escape) The Crying Game.
\end{abstract}

Keywords:Trans Cinema, Spectatorship, Gaze, Agency, Queer Theory 
There is really nothing more to say except why.

But since why is difficult to handle, one must take refuge in how.

Toni Morrison, in The Bluest Eye (1969).

Neste texto me proponho a discutir um recorte do filme Traídos pelo Desejo (The Crying Game$^{1}$, 1992), através do conceito de Tras Cinema² e do que gostaria de chamar de "válvula de escape". Antes de partir para a discussão de meu recorte do filme, apresento rapidamente esses dois conceitos, que me serão úteis para o argumento que busco desenvolver na discussão do recorte. Outro conceito importante, mas que será apresentado posteriormente, juntamente com o próprio recorte fílmico, é o de gaze, de olhar. Esse último conceito, como veremos, já tem extenso debate dentro da crítica feminista de cinema.

O que se tem convencionado chamar como Trans Cinema se constitui como um campo de filmes heterogêneos, que podem se definir como um subconjunto de filmes que se afirma através da existência de um ou vários personagens centrais dissidentes de gênero (em filmes de ficção ou não).

Estes filmes exploram aspectos-chave da incorporação trans ${ }^{3}$, que podem ser várias coisas, tais como: a negociação de que a incorporação da pessoa trans "passe" ou não como pessoa cis"; a

\footnotetext{
${ }^{1}$ Continuarei, ao longo do texto, a utilizar o título do filme em inglês, devido a relação com a canção homônima e sua importância para esse trabalho.

2 Prefiro manter o termo Trans Cinema, ao invés de traduzi-lo como Cinema Trans. Minha preferência se deve ao fato de que esse é um campo relativamente novo e a tradução de termos implica em muitas escolhas. Como estudioso cis que se interessa por filmes desse campo não me sinto autorizado a promover a tradução desse termo ou fazer escolhas tradutórias que seriam, me parece, mais adequadas de serem feitas por pessoas trans.

${ }^{3}$ Trans é um termo que pode ser usado tanto para referir-se a transgêneros como a transexuais, é um termo que não faz distinções entre transexualidade e transgeneridade. Enquanto a transexualidade é por vezes entendida como referindo-se a uma pessoa submetida a uma transição hormonal e médica (e/ou também diagnóstico médico de "disforia de gênero"), transgênero é usado para referir-se a pessoas que não estão submetidas ao mesmo processo clínico. Na prática, porém, transgênero pode representar a ambos - e, além disso, podemos argumentar que essa distinção destas duas práticas seja desnecessária e essencialisante e, até mesmo, redundante porque transições acompanhadas de intervenções hormonais ou não, muitas vezes, se misturam, substituem, se repetem, se recusam, se "queerizam" de várias maneiras. Assim, nesse texto, o trans aparecerá como um nome e não como um mero prefixo e sem que "gênero", "sexual", "sexualidade" sejam suas raízes necessárias, a fim de enfatizar os múltiplos fatores que tornam desnecessários e problemáticos suas diferenciações.

${ }^{4}$ Termo usado para descrever uma pessoa que não alterou o sexo ou gênero que lhe foi atribuído ao nascer. A importância do uso deste termo para dirigir a uma posição assegurada de privilégio de gênero, em comparação com uma posição trans. Posições de privilégio, muitas vezes, não são nomeadas. O termo cis permite uma nomeação desse privilégio e ao aumento da visibilidade das relações sociais de poder. Isso evita que a situação em posições de privilégio permaneça anônima, enquanto aqueles que "desviam" são destacados através de termos particulares. Cis oferece uma intervenção para isso. Ao longo dos últimos anos, este termo tem sido cada vez mais utilizado dentro do feminismo queer, e das comunidades trans e transfeministas. Além de destacar o privilégio, o termo também tem lados problemáticos que têm crescido com seu uso desde o início (AG Einleitung 2011; Enke 2012b, 60). Nessa discussão crítica, argumenta-se que o temo cis um dualismo essencializante entre as posições trans e posições não-trans que apresentam sexo como estáveis e coerentes (cis como a posição de que não mudou desde nascimento) e parecem
} 


\section{Dil: The Crying Game, espectatoralidade e agenciamento trans em Traídos pelo Desejo}

transição (de cis para trans) e suas repercussões no contexto social, bem como para o personagem em transição; a negociação da intervenção médica ou não; diferentes abordagens do corpo em transição, orientação sexual e sexualidade; pressões sociais e a necessidade de sobreviver, para garantir as necessidades existenciais, e para estar ou ficar seguro no mundo. Esses filmes também apresentam temas sociais e políticos, tais como parentesco, relacionamentos e amor, o racismo, "saúde" mental/deficiência, precariedade financeira, segurança, envelhecimento, ou sucesso profissional - para citar apenas alguns.

O termo Trans Cinema destina-se a resistir a qualquer noção essencializante ou fixa da identidade de seus protagonistas. Em todo o espectro de possíveis nomeações trans, sejam populares, críticas ou médicas, não tenho interesse neste estudo cine-cultural e transfeminista de estabelecer posicionamentos de gênero desses personagens. A nomeação de um grupo de filmes como Trans Cinema pode ser apenas temporário, especialmente porque o campo de estudos trans passa por rápidas trans-formações e se apresenta altamente produtivo em sua redefinição constante de termos, posições, palavras e materiais (Leung 2012, 185). Neste sentido, uma abordagem trans de escrita apresenta um desafio cronopolítico e espacial. Minha linguagem, minhas práticas que definem e descrevem, e minha escolha de pronomes e categorias já poderiam estar ultrapassadas pelo tempo no momento mesmo dessa publicação ou de sua leitura.

A discussão que proponho nesse texto tem como chave de leitura o que chamaria de "válvulas de escape". As "válvulas de escape" são momentos de intenso engajamento fílmico que permitem uma fuga temporária do domínio cinematográfico dos efeitos negativos de cenas constrangedoras que, como o estudioso de filme trans Jonathan Williams conclui, em sua pesquisa sobre audiência, cria medo e trauma para os espectadores trans (Williams 2011, 123).

As "válvulas de escape" são as cenas em que o personagem trans experimenta uma ruptura com o sentimento de medo ou da exposição a potencial violência. Estas cenas podem ser observadas em alguns filmes nos momentos em que o personagem trans sonha, está absorvida com uma música, ou está imerso em uma dança ou num mundo imaginário de fantasia e sonhos.

O termo escape me reporta para os conceitos de ethnoscape, mediascape, financoscape, ideoscape e tecnoscape cunhados pelo etnógrafo Arjun Appadurai. Ele trabalha com estes cinco "escapes" ou fatores globais, definidos como aqueles momentos que produzem fluxo cultural global e neutralizam qualquer ideia de homogeneização cultural (Appadurai 2006, 588). A noção de "válvula de escape", que proponho nessa discussão, também fala de fluxo cultural e é inspirado na 
NORUS - v3, n.3, jan - jun 2015.

ênfase de Appadurai em imaginar uma força de transformação social (Appadurai 2006, 587). O conceito de "válvula de escape" remete, ainda, a um evento muito especial dentro do Trans Cinema em que uma oportunidade de se desidentificar com as cenas de constrangimento aparece.

Portanto, abordar o Trans Cinema através da ideia de "válvulas de escape" é desenvolver uma estratégia que está ancorada em um modo de leitura desidentificatória do filme. A desidentificação apresenta um nível de agência, no confronto com o material cultural em que a existência de subjetividade culturalmente marginalizada é silenciada. Em Disidentification: Queers of Color and the Performance of Politics (1999), o teórico dos estudos culturais e queer José E. Munoz discute as práticas de artistas performáticos queer latinos e afro-americanos. A desidentificação apresenta um modo de negociar com a ideologia dominante que está incorporada dentro de estruturas dominantes - é uma estratégia "que funciona em e contra a ideologia dominante" e pretende "transformar a lógica cultural a partir de dentro". É uma prática cultural que se agarra em objetos problemáticos, e apesar de tudo tenta muda-lo e "investi-lo com vida nova" (Munoz 1999, 12). Nesse sentido, um modo de envolvimento desidentificatório com Trans Cinema permite a possibilidade de vislumbrar saídas para os personagens trans, envolvimento em trocas apaixonadas, anti-identitárias e transformadoras nesses filmes.

Talvez, valha o risco de parecer redundante e dizer que neste texto eu me concentro em um longa-metragem de ficção, que, em comparação com curtas-metragens, muitas vezes permite que várias "válvulas de escape" apareçam dentro de um filme, oferecendo-me um complexo dentro do contexto mais amplo de um filme. Delimitar-me em um longa de ficção dentro do Trans Cinema é uma estratégia textual, bem como processual, mas que se recusa a oferecer uma hierarquização em relação a outros gêneros possíveis dentro do campo do Trans Cinema. Ao contrário, o Trans Cinema, no meu entendimento, é uma assemblage móvel, mutável e heterogêneo de filmes.

\section{O filme - contexto e problemática}

The Crying Game, do diretor Neil Jordan é um filme que recebeu difusão da imprensa e atenção da mídia, bem como acendeu discussões acadêmicas sobre a representação da protagonista principal, Dil, como uma personagem feminina trans negra e as diversas formas de sua objetificação no filme (Kostsopoulos \& Mills 1994; Handler 1994; Edge 1995; Ayers 1997; DuttaAhmed 1998; Serano 2007; Yekani 2007; Grist 2003). Dentro do corpo geral de filmes do Trans Cinema, Dil se apresenta como uma das raras personagens trans negras nos contextos da Europa Ocidental ou no contexto norte-americano. Outra exceção é o filme Gun Hill Road (2011), cuja personagem é latina e interpretada pela atriz trans Harmony Santana. 


\section{Dil: The Crying Game, espectatoralidade e agenciamento trans em Traídos pelo Desejo}

Durante seu processo de produção, The Crying Game passou por graves dificuldades financeiras e foi produzido como uma produção de baixo orçamento de 2300 mil dólares. Jordan começou a rodar o filme com quase nenhum orçamento, o que ele mais tarde em uma entrevista relacionou com as questões políticas, de sexualidade e gênero presentes no filme (Cummins de 2012). The Crying Game foi um fracasso nas bilheterias do Reino Unido, levantando apenas 2 milhões de dólares, em contraste com o seu grande sucesso nos EUA, onde a bilheteria alcançou um bruto de 68 milhões de dólares. O fracasso de The Crying Game no Reino Unido é atribuído à temática política do filme, relacionada ao IRA $^{5}$ e aos "problemas" da Irlanda (Grist 2003, 4). Nos EUA, esta crise nacionalista britânica era muito menos conhecida e, portanto, a imprensa e a publicidade para o filme estavam preocupadas principalmente com a sua representação da sexualidade, orientação sexual e incorporação de gênero. Este aspecto do filme foi reforçado por uma estratégia de marketing da produtora, a Miramax, que se apressou em evitar que a imprensa fizesse uma avaliação especial estratégica em que a identidade trans de Dil não fosse mencionada e atraísse expectadores cis através do efeito de choque quando suas suposições sobre o corpo de Dil não fossem confirmadas (Grist 2003, 4).

$\mathrm{O}$ filme foi indicado a vários prêmios e ganhou vários deles. $\mathrm{O}$ ator principal, Jaye Davidson $^{6}$, um "recém-chegado" naquele tempo, foi indicado para melhor atriz, bem como melhor ator - uma expressão de problemas de gênero que este filme envolveu não apenas intradiegeticamente, mas também entre os membros do júri nos festivais. $O$ filme recebeu seis indicações para o US Academy Awards e ganhou o prêmio de Melhor Roteiro Original. Na GrãBretanha The Crying Game também foi indicado para os britânicos Academy Film Awards, em seis diferentes categorias e ganhou o Prêmio de Melhor Filme. Vários outros prêmios altamente reconhecidos se seguiram, entre outros, o ASCAP Film and Television Music Awards, o Australian Film Institute Award, o European Film Award, The Independent Spirit Awards, London Critics Circle Film Awards, Los Angeles Critics Association Awards, National Board of Review Award e o National Society of Film Critics Award, bem como uma nomeação para o Golden Globe Awards.

\section{Cantar, olhar, deixar-se olhar}

\footnotetext{
${ }^{5}$ Irish Republican Army - Exército Republicano Irlandês

${ }^{6}$ Após a exibição do filme instaurou-se a polêmica se Jaye seria indicado como melhor ator (como no caso do Oscar) ou melhor atriz (como no caso de diversos festivais). A polêmica foi motivada tanto pelo personagem de The Crying Game como pelos aspectos andróginos do ator, que em algumas entrevistas afirmou ter sido muitas vez, em sua vida pessoal, confundido como mulher. Depois de sua indicação ao oscar como melhor ator coadjuvante, a polêmica seria como Davidson apareceria vestido na cerimônia de premiação, se em roupas consideradas masculinas ou em roupas consideradas masculinas. Jaye Davidson teve que chegar muito antes à cerimônia e entrar pela porta dos fundos para evitar o assédio, vestindo uma roupa de gênero neutro.
} 
Dil está a trabalhar como cabeleireira em Londres, enquanto Fergus (Stephen Rea), um membro do IRA, é parcialmente responsável pela morte de seu parceiro Jody (Forest Whitaker), que era um soldado britânico estacionado na Irlanda. Após a morte de Jody, Fergus procura por Dil em Londres, talvez para fazer amizade ou para protegê-la, presumivelmente porque ele esteve próximo de Jody e está movido pela culpa que sente por sua morte. Fergus e Jody se tornaram amigos durante os dias em que Fergus e o grupo mantiveram este soldado britânico negro como refém ${ }^{7}$. Pouco depois de Fergus e Dil, que passa como uma mulher cis em seus vinte anos, se encontrarem, eles desenvolvem um relacionamento romântico, mas a princípio de maneira platônica, em que Fergus não revela como ele ouviu pela primeira vez sobre ela e o que constitui a sua conexão com ela.

Uma noite, Dil leva Fergus para casa com ela. Ela permite que ele a assista despir-se. Ele está olhando para seus genitais quando eles ficam expostos sem a camada protetora de seu vestido e roupa íntima. Fergus fica chocado quando ele vê que seu corpo parece diferente ao que ele esperava. Ele reage com repulsa ao que para ele é uma confusão visual de formas corporais normativas. Fergus corre para o banheiro, vomita e logo depois sai do apartamento. No entanto, depois desta noite, eles permanecem ligados e atraídos. Parece haver uma rede de razões variadas que os mantém juntos, que são elaborados principalmente através da perspectiva de Fergus. As motivações de Dil, portanto, permanecem um pouco obscuras.

Entretanto, a história deles começou poucos dias antes. Fergus havia encontrado o endereço de Dil e o lugar onde ela trabalha, um salão de cabeleireiro. Ele entra e, sem dizer muito, faz um corte de cabelo. Na noite seguinte, Fergus espera fora do salão até que a jornada de Dil acabe e segue-a através da ruas. Dil vai para o seu pub favorito, que também funciona como um clube até mais tarde da noite, o Metro. Fergus entra logo atrás dela e seus olhos se encontram, enquanto ambos bebem no bar. Dil, bem consciente de que ele a seguiu, se comunica com ele via o barman: "Pede para ele me perguntar o que eu gostaria de beber." Sem esperar pela resposta, ela imediatamente responde sua própria pergunta com o nome do cocktail e uma permissão: "Agora ele pode olhar"; uma afirmação que expõe seu comportamento assediador e através do qual ela assume o controle sobre a situação, implicitamente confrontando seu comportamento inadequado e o desmascarando. Após esta breve troca verbal e de olhares diretos, Dil é abordada por um amante ciumento. Fergus, mais uma vez, a segue, talvez curioso, para ver onde ela mora, ou a fim de ser

\footnotetext{
${ }^{7}$ Nos comentários sobre o filme, a relação entre Fergus e Frank é interpretada, muitas vezes, como homoerótica (Yekani 2007; Halberstam 2005). No entanto, é preciso alertar que ler Jody como um homem gay vinculado a Fergus é, também, uma forma de se recusar a entender Dil como uma mulher trans e continuar a lê-la com base nos marcadores convencionais de seu corpo como um homem cis homossexual. A visualidade e a força deste sentido como determinante, verdade a fornecer e dar prova, é um poderoso tema ao longo do filme.
} 


\section{Dil: The Crying Game, espectatoralidade e agenciamento trans em Traídos pelo Desejo}

protetor. No entanto, embora testemunhando o comportamento abusivo de seu amante, ele não interfere.

Na noite seguinte, Fergus aparece novamente no Metro. Desta vez, o bar está lotado, é algo como uma noite de palco aberto ou uma noite de várias performances. Há pessoas dançando, conversando, se apertando pelo bar para conseguir uma bebida. Eles são uma multidão queer; todos os tipos de pessoas com diferentes expressões de gênero e sexo estão espalhadas pelo lugar. Parece que Fergus não percebe que ele é provavelmente o único homem cis hétero no clube. Ele se senta no bar, o barman reconhece-o e dá-lhe uma bebida. Em algum momento ele se inclina, prestes a dizer algo para Fergus sobre Dil, que não está presente. A meio caminho, ele pára... Dil aparece no palco. Sabendo que Dil é trans, ele estava prestes a revelar a Fergus.

\section{A música, a performance - o escape}

Primeiro alguns acordes chamam a atenção do público para o próximo ato no palco. Então a voz de Dil aparece, junto com sua mão estendida de por trás da cortina do palco, fazendo movimentos delicados e femininos que parecem assemelhar-se aos movimentos da mão da dança "oriental". No momento em que ela começa a cantar, ela está inteiramente no palco, a câmera a mostra em plano amplo e médio close. Seu cabelo é meio longo, cacheado, alguns fios soltos cobrem parcialmente seu rosto, brincos em forma de esferas vermelhas que brilham nos lados de seu rosto. Ela está usando um vestido de lantejoulas douradas com um padrão colorido. Ela canta a canção em sua própria voz, ela não dubla, e sua voz é ambiguamente profunda, em entendimentos convencionais de voz codificada como feminina.

I know all there is to know about the crying game / I've had my share of the crying game / first there are kisses, then there are sighs / And then before you know where you are / you're sayin' goodbye...

Enquanto ela canta, ela está muito firme no palco, apenas movendo os braços em movimentos lânguidos expansivos, assim como também abriu sua canção com gestos das mãos. Seu vestido abrange seus braços e deixa as pernas mais expostas.

Fergus fica perto do bar e observa sua performance. Ele, provavelmente, ignorava até esse momento que ela também é uma cantora e performer. Enquanto Dil está no palco, ela está totalmente imersa na música, nos gestos. Mesmo que ela tenha notado Fergus no salão, ela nunca

\footnotetext{
${ }^{8}$ Eu sei tudo que há para saber sobre esse "jogo de chorar"/ Eu tive minha parte nesse jogo/ primeiro são os beijos, então os suspiros/ e então antes que você saiba onde está/ você está dizendo adeus.. (tradução livre minha)
} 
olha para ele. Ela permanece como a única a ser olhada, mas ela também permanece confortavelmente em seu próprio mundo, a música, o bar lotado, num momento em que não se deixa distrair pelo olhar de flerte de Fergus.

Esta canção se tornou famosa através da interpretação de Boy George, da qual se produziu a trilha sonora de The Crying Game em 1992. A versão original foi cantada por Dave Berrie, que se tornou um hit no Reino Unido em 1964. A versão de Boy George foi produzida pela banda Pet Shop Boys, que desde 1994 têm sido abertamente bissexual e gay e tem interpretado uma grande variedade de músicas de ícones da música de gay a queer, dentre os quais Dusty Springfield, Madonna, Elton John, Liza Minnelli e Kylie Minogue (Ruhlmann 2014). Boy George foi um dos primeiros cantores a sempre declarar abertamente orientações sexuais queer, que vão desde a assexualidade à bissexualidade e gay. Suas performances de palco transgridem normas de gênero não só através de sua voz de falsete, mas também em seu gênero in between na sua persona de palco. Como uma das muitas influências, o ícone queer ${ }^{9}$ David Bowie teve um forte impacto sobre ele como um artista, performer e cantor.

Neste sentido, a música tem uma base queer que poderia ser facilmente lida como contribuindo para uma leitura deste filme como gay, como tem sido percebido pela maioria dos críticos em uma normalização da forma de incorporação trans de Dil em uma cis-gay identidade. Mas deve-se ler Boy George e seu mentor David Bowie não só como gay, mas, principalmente, como uma "transgressão" de gênero marcado por um "transicionamento" da performance musical, essa música situa-se dentro de uma história de escrita da canção e performance musical dissidentes em termos de género.

A letra da canção explicitamente fala de uma pessoa que está familiarizada com a mágoa, o desespero e grande sentimento de perda quando um parceiro sai ou morre. Dil perdeu seu parceiro Jody e está mergulhada em grande tristeza. Sua performance no escape da música parece ser a única escolha adequada para ela cantar em tal estado de solidão e tristeza. Como uma canção, "The

\footnotetext{
${ }^{9}$ Nesse parágrafo, e em outros trechos desse texto, tenho utilizado os termos "queer" e "gay". Gostaria de diferenciar meu uso desses termos. Enquanto utilizo gay em termos mais identitários, utilizo queer em termos de identidades sexuais e de gêneros menos fixas ou questionadoras de normas rígidas de identidade, que podem ser consideradas desafiadoras do regime de identidade binária que vem "organizando" os modelos de relacionamentos e os modos de viver a identidade desde o Iluminismo (vale lembrar que essa é uma das muitas maneiras de pensar e historicizar as identidades). Queer pode ser traduzido como estranho, raro, esquisito e já foi um termo pejorativo para referir-se aos sujeitos da sexualidade desviante, tais como homossexuais, bissexuais, pessoas trans, drags, etc. Nas palavras de Guacira Lopes Louro (2004, pp. 7 - 8) "é o excêntrico que não deseja ser 'integrado' e muito menos tolerado." Portanto, corro, nesse texto, o risco da contradição ao classificar algum artista como "queer", se queer não serviria como identidade. Corro esse risco na tentativa de destacar que esses artistas e outros (podemos lembrar, no caso do Brasil, de Ney Matogrosso e do grupo Dzi Croquettes) desafiam a ordem da matriz heterossexual, desviam as expectativas de gênero, deturpam uma relação simétrica entre corpo masculino e performance masculina em nome de um embaralhamento que constrói outros corpos e produz outras performances, pois como continua Louro o "queer é um jeito de pensar e ser que não aspira o centro nem o quer como referência; um jeito de pensar e de ser que desafia as normas regulatórias da sociedade, que assume o desconforto da ambiguidade, do 'entre-lugar', do indecidível. Queer é um corpo estranho, que incomoda, perturba, provoca e fascina."
} 


\section{Dil: The Crying Game, espectatoralidade e agenciamento trans em Traídos pelo Desejo}

Crying Game" fala do pessimismo de não querer sentir algo tão intenso por alguém de novo, a fim de tentar evitar a vulnerabilidade emocional que o amor inclui. A canção fala da circularidade do "Crying Game" - seu retorno repetido, uma e outra vez, quando se abre o coração a alguém e o relacionamento chega ao fim, por várias razões.

As letras sombrias são acompanhadas por uma tonalidade desembainhada e melancólica. Os acordes menores da canção, juntamente com o conteúdo pessimista e saudoso da letra produz uma atmosfera dramática. Isto parece não só se reportar ao luto de Dil diante da morte de Jody, mas também prenunciar as dificuldades da relação entre Fergus e Dil, pois Fergus infligirá dor em Dil por não aceitar a forma de seu corpo, ter ignorado seus sinais e, mais tarde, depois que ela já estiver apaixonada por ele, deixá-la sozinha enquanto ele cumpre sua sentença de prisão por (?) suas atividades no IRA.

A performance de Dil da canção é executada com movimentos graciosos e elegantes. Minimalisticamente ela está no palco, cantando esta canção desesperada em sua bela voz, principalmente movendo apenas as mãos e depois os braços com a música. É um momento de decisão para Dil, é o momento em que ela abre seu coração para Fergus, com medo, mas também numa tentativa corajosa de entrar no "jogo" mais uma vez.

As condições desta canção-escape diferem significativamente da configuração geral da maioria dos outros filmes do Trans Cinema. Neste filme é a personagem trans mesma que executa uma canção. Em muitos desses filmes com personagens trans, eles/as são representados/as como ouvintes. Aqui Dil sobe ao palco por si mesma, semelhante ao personagem principal em Hedwig and the Angry inch (2001) ou no filme posterior de Neil Jordan Breakfast on Pluto (2005).

O Metro e o conjunto desse clube queer oferecem um dos raros momentos no Trans Cinema em que a personagem trans está inserida em um contexto queer e trans. Cenas semelhantes ocorrem brevemente no Transamerica (2005) quando Bree encontra o seu grupo de apoio feminino trans e no Romeos (2011) com a comunidade on-line de Lukas. No entanto, estranhamente, em todos esses filmes, e também no The Crying game, as personagens trans permanecem de alguma forma singular, socialmente independentes e sem quaisquer redes, em que se podem agarrar, sem amigos que vêm para abraçar, fofocar, rir. A comunidade é quase ficcional no modo como ela é representada, em particular nesta cena. Dil aparece no palco, ou no bar, mas permanece deslocada do resto da audiência. 
NORUS - v3, n.3, jan - jun 2015.

\section{O olhar - "now he can look"}

O bar é quase como sua casa. Ocasionalmente, seu namorado violento aparece, mas na maior parte, e agora especialmente no palco, ela capta o ambiente, assume o controle sobre os olhares, sobre a plateia, atraindo a atenção e dirigindo a tensão no salão, junto com o desejo de Fergus , em direção de si mesma.

Dil está sendo olhada por Fergus, que assiste a sua performance e, no entanto, eu diria, que ela não se torna um objeto passivo do olhar. Poucas noites antes que ela dera permissão, permitindo-lhe olhar, expondo seu desejo, ganhando controle sobre o posicionamento através de seu olhar. Eu compreendo sua performance como dando ênfase a esta frase, uma confirmação de seu interesse por ele, em sua aparência, que também significa atração; uma afirmação que se estabeleceu com confiança as regras para a sua futura conexão.

A Teoria feminista do cinema tem uma longa história de discutição do olhar (o gaze) enquanto objetivante da personagem feminina (Mulvey 1975; Doane 1999a; De Lauretis 1999). ${ }^{10} \mathrm{E}$, como a acadêmica dos estudos culturais Elahe Haschemi Yekani observa, um dos problemas de uma abordagem psicanalítica motivada para estruturas do olhar em filme é que ele permanece binário, ele só pode ver o masculino e o feminino e a questão da atração mútua. Assim o olhar não pode ser examinado para além do binário do gênero e Yekani aponta para uma questão interessante, a ausência de um questionamento sobre o potencial subversivo de um gênero posicionado no in between, ou ainda como o olhar afeta a construção de posições de gênero hetero cis (Yekani 2007, 264). Yekani discute a espetacularização de Dil em The Crying Game como uma estrutura que a constrói como um objeto fetichizado e sexualizado, explorado por um olhar masculino (Yekani 2007, 265). Esta estrutura é muito explícita ao longo do filme ainda que perceba um enfraquecimento do "olhar masculino" no canção-escape. Isso ocorre por meio das palavras de Dil, a música, a letra, tanto quanto através de sua frase para Fergus "Agora, ele pode olhar." Ela é a única responsável, quem pode ler o contexto, que tem o conhecimento, enquanto ele permanece alheio a ela, o bar lotado e seu contexto cultural.

\footnotetext{
${ }^{10}$ Desde que Laura Mulvey publicou, em 1975, o artigo "Visual Plesure and Narrative Cinema" emergiu uma intensa discussão a respeito do olhar, do gaze, masculino sobre as personagens femininas. A própria Mulvey, em trabalhos posteriores, como em “Afterthoughts on 'Visual Pleasure and Narrative Cinema' inspired by King Vidor's Duel in the Sun (1946)" revisitará esse conceito e introduzirá novos, como o conceito de espectadora. Muita da discussão se centrará tanto na problemática de uma suposta passividade das personagens femininas ao olhar masculino como sobre seus aspectos heterossexualizantes e binários. De alguma maneira esse texto, e outros que venho trabalhando, pretende, ainda que timidamente, entrar nessa discussão ao abordar a espectatoralidade e o agenciamento. Outra crítica fundamental que o artigo de Mulvey (artigo foi publicado no Brasil na coletânea "A experiência do cinema", organizada por Ismael Xavier) recebeu diz respeito à forte presença da psicanálise em seu argumento. Para uma contextualização da importância desse artigo de Mulvey, bem como da crítica feminista de cinema pós"Visual Pleasure", ver o texto "Políticas do Olhar: feminismo e cinema em Laura Mulvey" (MALUF et alii, 2005) e a entrevista com Laura Mulvey (2005), ambos publicados na Revista Estudos Feministas.
} 


\section{Dil: The Crying Game, espectatoralidade e agenciamento trans em Traídos pelo Desejo}

Dil se torna o agente do olhar como ela utiliza o palco e a exposição visual para situar-se em um determinado contexto e se conectar a uma certa cultura. Ela é olhada e ainda assim ela mantém controle sobre como e quando alguém é permitido a olhar. Abordar sua performance e a dinâmica do olhar neste filme, e particularmente a música-escape, através de uma tal leitura afirmativa, ressoa com uma declaração do músico Elias Oberman da banda The Shondes. Oberman ao ser entrevistado no documentário Riot Acts: flaunting gender deviance in Music Performance (2009), do diretor trans Madsen Minax, fala sobre suas experiências no palco como um músico trans:

De certa forma, mesmo que você não tenha controle sobre como as pessoas vão vê-lo ... Eu me sinto provavelmente mais seguro no palco do que o contrário, porque há um certo elemento de controle lá - como se estivesse em um contexto de sua própria criação. Acho isso muito libertador (OBERMAN, 2009).

Aqui, Elias Oberman explicitamente aborda o fato de que nesta "espectatoralidade" reside o desconforto, tanto quanto o controle, dependendo do contexto. O elemento de controle é especialmente ativado para ele quando ele performa no palco. Dil também escolhe um palco para determinar seu terceiro encontro com Fergus e isso preludia sua primeira noite juntos em que Dil é confrontada com a reação de Fergus a sua incorporação trans. Nesta cena em que ela está cantando, ela se apropria do controle através do olhar (gaze) e dirige o olhar (look) de Fergus em seu corpo para que ele veja um corpo que é poderoso por sua performance eloquente, bem como vulnerável em sua interpretação melancólica das palavras da canção. Ela fala nesta canção de ambos estes aspectos e ainda, embora ela seja ouvida por Fergus, ele não está ouvindo corretamente, como o incidente mais tarde em seu apartamento demonstra.

\section{A espectatoralidade trans}

Participar nesta cena como um espectador parece ser exatamente o funcionamento desta sequência. Dil, embora, de alguma maneira, explorada no filme por um olhar cisnormativo e objetificante, se apropria da estratégia desta "espectatoralidade" e a usa em seu favor, em vez de voyeuristicamente contra ela, como também argumentou, em diferentes artigos de estudos culturais, Judith Jack Halberstam (Halberstam 2005, 81). No entanto, a posição controladora de Dil não ressoa com a discussão de Halberstam do olhar trans. Parece que os diferentes olhares trans possíveis que Halberstam sugere nas suas discussões sobre Trans Cinema em In a Queer Time and Place não se aplicam a este filme e esta cena particular. Em sua discussão anterior sobre o olhar trans, Halberstam discute Boys don't Cry e singularmente centra-se no modus de um "embedded looking" - a possibilidade de observar a paisagem através da perspectiva do personagem trans (Halberstam 2001, 294). No livro In a Queer Time and Place, Halberstam desenvolve melhor essa 
NORUS - v3, n.3, jan - jun 2015.

discussão e propõe para o olhar trans mais três modi. O modus "retrocesso", olhar que descreve uma situação em que o personagem trans passa pela primeira vez como um personagem cis seguido por um outing ${ }^{11}$ do personagem como trans e este apresenta um clímax narrativo central. O próximo modus é "fantasma", onde o personagem trans é integrado ao filme depois de sua morte, por exemplo, através de voice-overs. E o último modus apresenta a estratégia de "duplicação", onde o personagem trans não permanece o único personagem dissidente de gênero em um filme (Halberstam 2005, 78).

Como espectador, nunca é possível olhar para o cenário através dos olhos de Dil ("olhar embedded"); não há "fantasma" ou "duplicado" também. E mesmo que o "olhar retrocesso" estivesse presente, ele não é um olhar encorajador, mas é integrado na cena de "coming out" com uma tomada de corpo nu que provocou reações intensas, tanto no cinema, onde as audiências protestavam ou saiam da sala durante esta cena inesperada, bem como intra-diegeticamente, em que a reação de Fergus revela-se transfóbica. Nenhuma destas estruturas do olhar funciona para o benefício de Dil. Em vez disso, o olhar se apresenta numa exotização de Dil, integrando-a como um espetáculo, como uma "figura-fetiche racializada" (Halberstam 2005, 81) para distrair e simultaneamente melhorar a estrutura nacionalista do enredo do filme. Apesar destas leituras pessimistas das estruturas do olhar, eu diria que essa "espectatoralidade" torna-se uma ousadia consciente do olhar - uma "espectatoralidade agencial". Dil confiantemente escolhe ser observada; um olhar que é permitido e até mesmo imposto por ela. Continuar no palco e realizar sua performance foi sua decisão e é algo que ela gosta. Dil utiliza a música e sua performance no palco para melhorar a sua posição dentro do clube, se reapropriar e desviar um olhar explorador e utilizálo para afirmar seu posicionamento dentro da comunidade gay e trans que frequenta este bar.

Esta cena também mostra como uma análise do olhar sozinho e sua construção do protagonista feminina como objetificado e passivo não é suficiente para abranger a complexidade da dinâmica cinematográfica que não só ultrapasse o binário do gênero (Halberstam 2005; Yekani 2007), mas também vá além de uma análise visual e inclua a atividade intra-multisensorial que está presente no filme, especialmente através da canção-escape. A música torna-se uma saída, uma vez que se torna o momento de expressão de Dil, em que ela aborda o público, Fergus, usando a música para posicionar-se, emocionalmente tanto dentro de uma determinada cena como em forma de

\footnotetext{
${ }^{11}$ Outing é um termo usado frequentemente nos estudos gays, lésbicos e queer para referir-se aos atos ou performances de revelação da identidade sexual. A teórica queer Eve K. Sedgwick tem um importante livro chamado "Epistemology of the closet" e um dos artigos desse livro foi publicado nos Cadernos Pagu com o título "Epistemologia do Armário" (SEDGWICK, 2007). Nesse texto, Sedgwick demonstra como a revelação da identidade sexual ou a "saída do armário" representa para a comunidade gay uma espécie de saber, que envolve muitas situações de contradição e abre e fecha portas de armário em diferentes contextos. Sedgwick argumenta que ninguém está sempre fora do armário, há sempre algum momento em que a revelação não acontece instantaneamente e que a revelação de alguém pode significar também a revelação de outros.
} 
Dil: The Crying Game, espectatoralidade e agenciamento trans em Traídos pelo Desejo

incorporação específica. A música-escape torna-se um espaço de reapropriação para Dil, como um instrumento pelo qual ela se expõe - a objetificação - e se apropria dele a fim de estabelecer-se e produzir um espaço para si mesma. No contexto do filme, a música, sua tonalidade, letra e contexto de interpretação intra-diegeticamente gera a sequência como "válvula de escape" para o espectador. Esta música-escape proporciona um momento em que se pode ouvir as palavras de Dil, palavras que ela escolheu para trazer ao público, um momento confiante, tanto como uma situação em que ela se apropria de uma identidade segura. Ele apresenta uma saída-escape utópica em seu encorajamento no sentido de exposição, abertura, compromisso e coragem.

\section{REFERÊNCIAS BIBLIOGRÁFICAS}

APPADURAI, Arjun, Disjuncture and Difference in the Global Cultural Economy. In: DURHAN, Meenakshi Gigi \& KELLER, Doublas, Media and Cultural Studies: keyworks. Victoria: Blackwell, 2006.

AYERS, M. kathryn, The Only Good Woman, Isn't a Woman at all: The Crying game and the Politics of Misogyny, Women's Studies International Forum, Vol. 20, No. 2, 1997

CUMMINS, Steve, Interview: Five Minutes With... Irish Filmmaker Neil Jordan, Disponível em: http://iftn.ie/news/?act1=record\&only=1\&aid=73\&rid=4285314\&tpl=archnews\&force=1

DUTTAAHMED, Shantanu, "I Thought You Knew!": Performing the Penis, the Phallus, and Otherness in Neil Jordan's The Crying game”, Film Criticism, Vol. 23, No. 1, 1998.

DOANE, Mary Anne, Caught and Rebecca: The Inscription of Femininity as Absence. In: THORNHAM, Sue Thornham, Feminist Film Theory: A Reader. Edinburgh: Edinburgh University Press, 1999.

DE LAURETIS, Teresa, Oedipus Interruptus. In: THORNHAM, Sue Thornham, Feminist Film Theory: A Reader. Edinburgh: Edinburgh University Press, 1999.

EDGE, Sarah, “Women Are Trouble, Did You Know That Fergus?': Neil Jordan's The Crying game, Feminist Review, No. 50, 1995

ENKE, Anne Finn, The Education of Little Cis: Cisgender and the Discipline of Opposing Bodies. In: ENKE, Anne Finn, Transfeminist Perspectives: In and Beyond Transgender and gender Studies. Philadelphia: Temple University Press, 2012

GRIST, Leighton, "It's Only a Piece of Meat": Gender Ambiguity, Sexuality, and Politics in The Crying game and M. Butterfly”, Cinema journal, Vol. 42.No. 4, 2003.

HALBERSTAM, Judith Jack, The Transgender Gaze in Boys don't Cry, Screen, Vol. 42, No. 3, 2001 
NORUS - v3, n.3, jan - jun 2015.

HALBERSTAM, Judith Jack, In a Queer Time and Place: Transgender Bodies, Subcultural Lives. New York: New York University Press, 2005

HANDLER, Kristin, Sexing The Crying Game: Difference, Identity, Ethics, Film Quarterly, Vol. 47, No. 3, 1994.

KOTSOPOULOS, Aspasia \& MILLS, Josephine, "The Crying Game: Gender, Genre and "Postfeminism", 1994 In: Jump Cut: A Review of Contemporary Media. Disponível em: http://www.ejumpcut.org/archive/onlinessays/JC39folder/CryingGameK-M.html

LEUNG, Helen Hok-sze, Trans on Screen, In: CHIANG, Howard Transgender China, New York: Palgrave, 2012

LOURO, Guacria Lopes, Um corpo estranho: ensaios sobre sexualidade e teoria queer, Belo Horizonte, Autêntica, 2004.

MALUF, Sônia Weidner (et alii) Políticas do olhar: feminismo e cinema em Laura Mulvey, Revista Estudos Feministas, vol. 13, No. 2, 2005.

MULVEY, Laura, Entrevista com Laura Mulvey. Revista Estudos Feministas, Florianópolis, vol. 13, No. 2, 2005. Disponível em: http://www.scielo.br/scielo.php?script=sci_arttext\&pid=S0104026X2005000200008\&lng=en\&nrm=iso.

. Visual Pleasure and Narrative Cinema, Screen, vol. 16, No. 3, 1975.

MUÑOZ, José Esteban, Disidentifications: Queers of Color and the Performance of Politics, Minneapolis: University of Minnesota Press, 199.

RUHLMANN, William, Review, 2014, Disponível em: http://www.allmusic.com/album/thecrying-game-sbk-mw0000095128

SEDGWICK, Eve Kosofsky, Epistemologia do armário. Cadernos Pagu, Vol. 28, No. 1, 2007.

SERANO, Julia, Whipping girl: A Transsexual woman on Sexism and the Scapegoating of femininity. Berkeley: Seal Press, 2007

WILliANS, Jonathan, Trans Cinema, Trans viewers. PhD dissertation. Melbourne: University of Melbourne, 2011. 